\title{
The Relationship between Self-Efficacy and Academic Achievement in Adults' Learners
}

\author{
By Maria de Fátima Goulão*
}

This paper examines the relationship between the academic selfefficacy of an adult learners group in an online learning context with their actual performance. Our study aims to evaluate the relationship between self-concept of a group of students in online context and their academic achievement. Data were collected from 63 students of both genders, with average age of 42 years old, selected from the first years of their undergraduate studies. We analyzed their performance in academic course specifies. An adapted questionnaire was used to measure self-efficacy $(\alpha=.908)$. The data was analyzed using descriptive and inferential statistics. The Pearson correlation coefficient was used to see the relationship between self-efficacy and academic performance. The analysis of the data indicated that students' level of self-efficacy is high (average $=45$ ) and a significant relationship exists between selfefficacy and academic achievement ( $r=0.286$, at 0.05 level).

\section{Introduction}

The concept of self-efficacy is related to the belief that everyone has to evaluate their abilities to perform a given task successfully. This concept has a strong influence on the approach to the task, the persistence to accomplish the same, as well as the level of effort. There are several studies that show a correlation between the level of self-efficacy and academic results. In an online learning system that requires students' greater autonomy, as well as a higher level of persistence and effort in the learning tasks. To be aware and know the degree of self-efficacy of students seems particularly relevant.

\section{The Adult Learner and Online Learning Context}

According to Merriam \& Brockett (2007) when we are talking about "adults" and "education" is necessary to distinguish two concepts - adult education and adult learning. According to these authors adult learning is a cogntive process internal to the learner; ... So while learning can occur both incidentally and in planned educational activities, it is only the planned activities that we call adult education (p.6)

\footnotetext{
*Assistant Professor, Aberta University, Portugal.
} 
Many of the learners who resort to distance learning, in general, are no longer youths and they have their jobs and their families. Therefore, they have to coordinate different areas of life which influence each other.

The reasons that lead them to embrace a project in distance learning are quite varied. Some learners bet in getting a higher education degree, in order to achieve a better job, while others only want to increase their culture. If in a more traditional distance learning can talk in greater isolation of students, with the introduction of information and communication technologies, the creation of online contexts such as learning support system, this situation began to reverse itself. The creation of common spaces - the virtual classroom - the use of synchronous and asynchronous communication tools enables learners and teachers a new management of learning situations. The online contexts allow greater flexibility and diversity of formats, interactions and answers to the needs of those who resorted to it. The virtual environment is seen as a new framework with features and elements of its own. The idea of time and space takes on a new perspective because it allows gathering people at various and deferred time and spaces. Allows for constant updating and network thinking, where the non-linearity of communication is seen in different ways, individually or multi-directional.

As already mentioned, the public that attends to virtual classes is typical adult. The different changes that occur at different levels, make learning not only occurs in a given period of time, it is increasingly required to the subject a constant learning throughout the life cycle.

The question of the specificity of the adult learner already has a few years. This issue led to the development of the movement called Andragogy, or "the art of teaching adults." The principal name that is connected to it is the Malcolm Knowles (2012). For him the adults are self-responsible and expect to have responsibility for taking decisions.

Andragogy is based on fundamental assumptions for adult learners. Let's see what these assumptions are.

1. Self-concept of the learner. Once the adults have reached a stage where they have responsibility for their lives, develop a psychological need to be seen and treated by others as being able to self-manage.

2. The role of the experiment. Adults go to a learning situation with a larger number and greater diversity of experiences than children.

3. Orientation to learning: Adults are ready and motivated to learn. The results of this learning are related to the context of life that helps them to deal and to solve problems.

4. The need to know. Adults need to know why they have to learn certain subject before engaging in the task.

5. Motivation. The best motivation is intrinsic, such as self-esteem, quality of life and an increase in employment. 
The studies of Rogers (1985) also point out to the benefits that adults can get in learning when they become responsible for it, ie, defining goals, select sources or study materials, establish the successive steps, instill a certain rhythm and assess learning.

The involvement of the adult learner in the training is part of a story, a path of personal life. The decision that takes an adult to engage in a training process is, in one way or another, connected to a personal, professional and / or social project. That is, the involvement of an adult learner construction leads to a formation of expectations, who may not be fully aware, but which, at the end, he expects to see realized.

For Cross (1981) an adult learner invests in training, to the extent that expectations are so strong, and seen as important to him, that training is the way to achieve them. Thus, involvement in training mobilizes not only aspects of cognitive order, but also, as it should be, affective aspects. Different surveys agree at one point: the individual project is the starting point for essential and indispensable that takes an individual to start a training process. That is, this project is the main source of energy for everything to happen.

However, the involvement of an adult learner, in a training situation, may be complicated due to the existence of other parameters. That is often the adult learner is confronted with problems that relate to the fact that the adult has another type of liabilities / commitments, in addition to training. For instance, an adult may have family, business and sometimes social responsibilities.

Linked to adult education we found developments in the area of selfdirected learning. In this perspective the emphasis is on the adults and on them taking control of their learning, and the social context in which the learning takes place it is particular important. This way of thinking about learning is one of the most frequent choices of adults, there is a strong relation between it and self-concept.

The elearning gives the student time and space flexibility, allowing a better management that suits their needs in education. In these learning systems one of the most important roles of the teacher is being the mediator / facilitator. This means that the teacher should aim to provide appropriate educational aid to students' constructive learning (Goulão, 2012, p.29).

In an online education system, with an emphasis on the idea of a learner as a constructor of his own knowledge, aspects related to self-regulation and selfefficacy gain particular relevance.

\section{Self-Efficacy and Academic Achievement}

Self-efficacy determines how people feel, think, motivate themselves and behave. This concept is related to the beliefs that people have about their capacity to complete a specific task. This is constructed from the information arriving from a range of different sources, as it can be seen in Figure 1 (Bandura,1993, 1994; Bandura \& Locke, 2003). So, judgments of self-efficacy 
result from previous experiences / accomplishments, from vicarious experience (modeled by others), from social persuasion resulting after training and evaluative feedback, and from the physical and emotional conditions of the subjects.

Figure 1. Sources of Self-efficacy Information



Beliefs about self-efficacy have a significant impact on the definition of goals, and compliance through the influence they exert on individually choice, motivation, resilience, and on emotional reactions. These, on the other hand, will influence the effort and persistence in performing a given task. This means that self-efficacy influences either the cognitive or the affective dimension of the learning process.

However, when it comes to online contexts, the information sources may have other origins. The variables that influence self-efficacy in online contexts may come either from previous successes in online systems, anxiety towards technology learning, feedback from teacher / trainer or frequency of a pretraining course (Stone, 1993).

Bates \& Khasawneh (2007) attempted to study the influence on the perception of self-efficacy in online learning, the variables that precede the learning process and its repercussion on the expectation of result. For them the successes that students obtained in the past in online contexts influence their self-efficacy. So, they point out to the importance of adequate and premature training enabling students to meet and practice the different elements that a system of online learning provides. This point can connect to the feeling of ability to work / study / use a virtual learning system as an incorrect perception of this ability can influence the feeling of self-efficacy and, consequently, performance. The feedback provided by the teacher is another very important source of information to enhance / regulate the sense of self-efficacy.

\section{Method}

\section{Objectives}


The objectives of our research are to understand the relationship between the self-efficacy's feeling of an adults group learning in online learning context and:

a) what levels of self-efficacy do students have in a particulary course unit;

b) their performance in a particular course unit;

c) sociodemographic variables, such the gender of these learners.

\section{Design and Participants}

Data collection was made through the scale of the MSLQ self-efficacy adapted. A total of 63 elearning students participated in the survey, as volunteers; $19 \%$ males and $81 \%$ females; The average age of the participants was 42, ranging from 25 and 60 years old (see Table 1) five students were in their 20s, 24 students were in their 30s, 19 students were in their 40s, 14 students were in their 50s, and 1 student was in his 60s. The median age was 41.

Table 1. Descriptive Statistics of Participansts' Age

\begin{tabular}{llllll}
\hline Variable & N & MIN & MAX & AVG & SD \\
\hline Age & 63 & 25 & 60 & 42.17 & 8.82 \\
\hline
\end{tabular}

Material and Procedure

The first part of the questionnaire concerned the identification of the sample (age and gender).

Self-efficacy: In second part we used the scale of the MSLQ self-efficacy, adapted to the specific content and to the online environment (Appendix 1). The MSLQ was developed by a group of researchers in the University of Michigan to improve postsecondary teaching and learning. The complete MSLQ contains 15 different sub-scales, which can be used together or singly (Pintrich et al., 1991).

The questionnaire is composed by a set of 8 statements and with a response scale ranged between 1 and 7 . Students chose a number between 1 and 7 that best describes their position towards the statements. The number 1 means that the student fully disagrees with the statement, and the number 7 means that the student fully agrees with the statement.

Overall Academic performance: Students' overall academic performance was measured by their total grade which could come from two different types of evaluation. In the first group we have students with one final face to face exam (100\%); in the second group we have students with 2 criteria - two online works ( $e$-folio, $40 \%)$ during the semester and a final face to face exam ( $p$-folio, $60 \%)$

Participants were asked to complete the questionnaire online at their own place. The questionnaire was given once in time at the beginning of the school activities of the course, before they have been requested any evaluation 
activity, and therefore without having had any evaluative feedback on their performance in that course. However, this course belonged to the 2nd semester. Figure 2 presents the overall research procedure used in this study.

Figure 2. The Overall Research Procedure

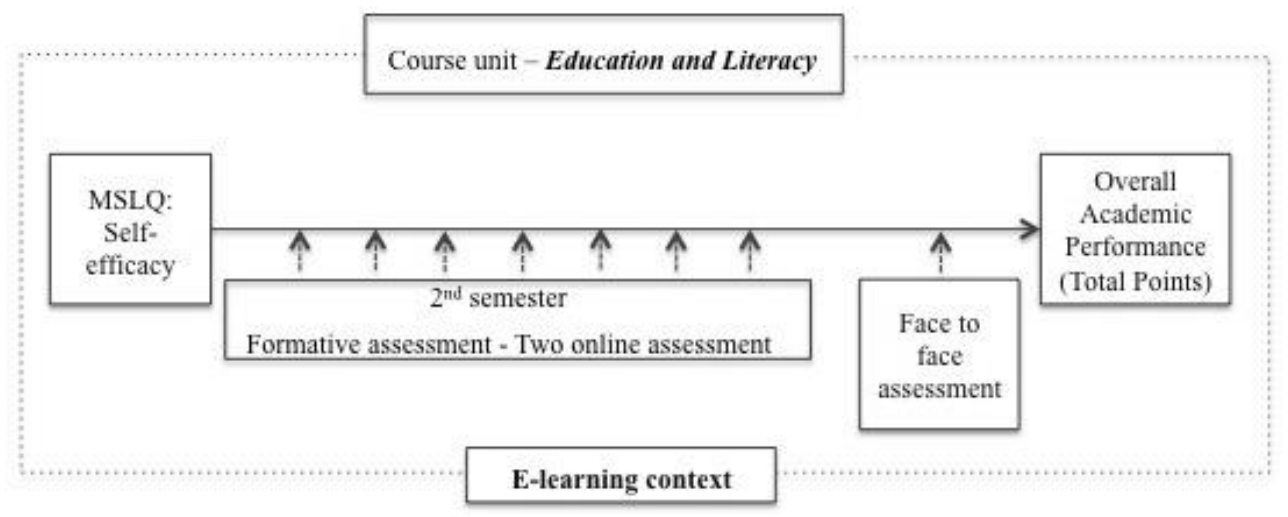

\section{Data Analyses}

We proceeded to the analysis of participants' responses according to how the questions were asked.

It was the purpose of this research to examine the variables gender and age behavior on the feeling of self-efficacy. It was also our purpose to examine the relationship between the feeling of self-efficacy and the actual performance of this group of students. To analyze the behavior of the variables gender, age, and performance we used the Pearson Correlation. To analyze the behavior of the variable gender we used the T Student test.

\section{Results}

We will present the results taking into account the three objectives of our research.

\section{Students' Self-efficacy Level}

Students' self-efficacy scores were analyzed to answer the first research question: What levels of self-efficacy do students have in a particularly course unit.

The average score for the 8 items of the MSLQ self-efficacy scale was $45.03(\mathrm{SD}=5.96)$ and the mode was 48 . The reliability statistics of this scale was $\alpha=.908$.

Figure 3 represents minimum and maximum range of the scale of selfefficacy (Min $=8$; Max = 56), and the Min, Max and average obtained by the students (45).

Figure 3. Representation of the Min, Max and Average Student Relatively to the Theoretical Minimum and Maximum Values on the Scale of Self-Efficacy 


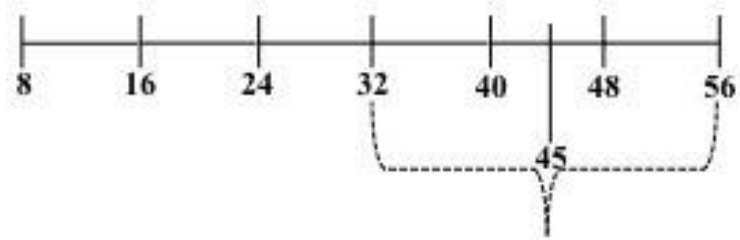

We will now present the results obtained in our study regarding the 8 questions of scale of self-efficacy by comparing them to the results obtained in the investigation of Pintrinch at al (1991).

Table 2. Comparing Descriptive Statistic from Pintrinch at Al (1991) and this Study

\begin{tabular}{|c|c|c|c|c|c|c|c|}
\hline & \multicolumn{4}{|c|}{ Pintrinch et al } & \multicolumn{3}{|c|}{ This study } \\
\hline Variable & & $A V G$ & $S D$ & $\alpha$ & $A V G$ & $S D$ & $\alpha$ \\
\hline \multirow{8}{*}{$\begin{array}{c}\text { Self- } \\
\text { efficacy }\end{array}$} & Q1 & 4.95 & 1.59 & \multirow{8}{*}{.93} & 5.29 & .81 & \multirow{8}{*}{908} \\
\hline & Q2 & 5.18 & 1.62 & & 5.49 & 1.00 & \\
\hline & Q3 & 6.36 & .96 & & 6.06 & .95 & \\
\hline & Q4 & 5.36 & 1.48 & & 5.41 & .96 & \\
\hline & Q5 & 5.24 & 1.47 & & 5.52 & .91 & \\
\hline & Q6 & 5.55 & 1.39 & & 6.21 & .99 & \\
\hline & Q7 & 5.57 & 1.30 & & 5.49 & 1.15 & \\
\hline & Q8 & 5.55 & 1.34 & & 5.56 & .88 & \\
\hline
\end{tabular}

\section{Self-efficacy and Final Classification}

As we said earlier, we will now proceed to present the results obtained regarding the relationship between self-efficacy and the final classification (see Figure 3)

Figure 3. Relationship between Self-Efficacy and Classification

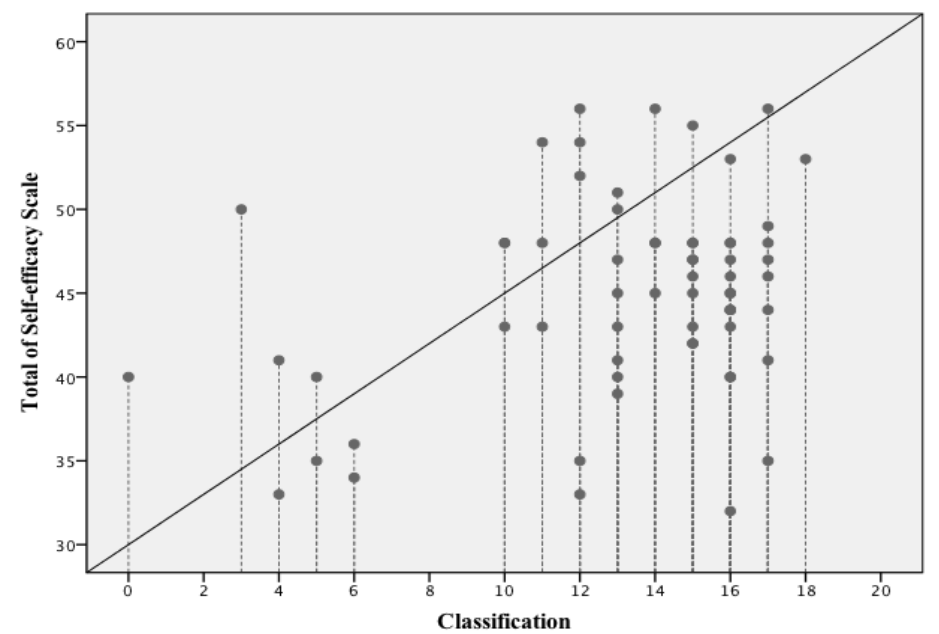

The results for self-efficacy were presented in the previous section. 
The 63 students had an average final classification of $13.40(\mathrm{SD}=3.69)$ on a scale of 0 to 20 . The median was 15 and the mode was 16 .

As can be seen the average level of self-efficacy of these students is reasonably high. To check the possible relationship between these two variables we used the Pearson correlation coefficient. The result $\left(r_{\mathrm{pb}}=.286\right)$ indicates a statistically significant relationship between the sense of selfefficacy indicated by these students and their level of academic performance, in this particular course. This correlation is significant at the .05 level.

\section{Self-efficacy and Gender}

We now present the results obtained for these two socio-demographic variables, beginning by analyzing the gender variable. To check if there are differences between men and women regarding self-efficacy we used the $T$ Student test. The results obtained are shown in Table 2.

Table 2. Results for the T Test by Gender

\begin{tabular}{cccc}
\hline & $\begin{array}{c}\text { Men } \\
(n=12)\end{array}$ & $\begin{array}{c}\text { Women } \\
(n=51)\end{array}$ & \\
& Mean (SD) & Mean (SD) & $t(63)$ \\
\hline $\begin{array}{c}\text { Self-efficacy (total } \\
\text { score) }\end{array}$ & $45.92(7.01)$ & $44.73(5.73)$ & $-.546(n s)$ \\
\hline
\end{tabular}

The result from applying Pearson correlation test indicates that there are no statistically significant differences between men and women regarding selfefficacy. The results $\left(r_{\mathrm{pb}}=-.073\right)$ in the correlation analysis between the variable gender and self-efficacy indicate an absence of a statistically significant correlation between them.

\section{Conclusions}

Our aim was, first, to analyze the level of self-efficacy do students have in a particularly course unit. Our results indicate a high level of self-efficacy in our sample. In addition, although we used a modified version of the MSLQ self-efficacy scale, the psychometric characteristics are in agreement with the values found in the original scale.

Secondly, to analyze the relationship between self-efficacy beliefs and the performance of a group of students in a particular course in the context of virtual learning. Finally, to examine these beliefs of self-efficacy based on gender. Our results point out of a statistically significant relationship between the self-efficacy and performance. These results seem to go in the same way to the other studies that usually find out a statistically significant relationship between performance and self-efficacy (Bates \& Khasawneh, 2007; Cascio et al, 2013; Taipjutorus, Hansen \& Brown, 2012). Regarding to our third goal linked to gender, the results do not indicate statistically significant differences between men and women in self-efficacy in this specific content and in a 
virtual learning system. These results do not meet some studies that indicate statistically significant differences between gender when it comes to selfefficacy associated with the use of computers or the internet (Eachus \& Cassidy, 2006), reinforcing the stereotype that Internet users are generally perceived as young and males. There are also other studies that found statistically significant differences between men and women when using the virtual space (Goulão 2013).

Despite the limitations of this study we must take into account the results obtained in what comes to the relationship between self-efficacy and performance of students. For this, we reiterate the importance of how virtual learning environments should be designed. These should provide positive experiences and to help the student to enhance their capacity for self-learning, self-regulated learning and motivation in the face of formal learning situations.

The teacher has an important role in defining / reorganization of the tasks of learning and formative assessment providing to the student appropriate feedback to their situation, to help them overcome difficulties, enhancing their skills, not only in terms of specific content matter, but also to the use of virtual learning environments potential.

For this reason, we would like to reinforce the important role that the preconditions have to start learning a course related to the acquisition / enhancement of skills in the use of technology and field of ways of working and interacting in these spaces to an increased feeling of self-efficacy in this context. This can be a facilitator of learning relationships between subjects, content and environment resulting in better performance.

\section{References}

Bandura,A, 1994. Self-efficacy. In Ramachaudran,V.S. (Ed.), Encyclopedia of human behavior (vol.4, pp.71-81). New York: Academic Press

Bandura,A,1993. Perceived self-efficacy in cognitive development and functioning. Educational Psychologist, 28(2),117-148

Bandura,A. \& Locke,E. 2003. Negative self-efficacy and goal effects revisited. Journal of Applied Psychology, 88 (1),87 - 99

Bates, R. \& Khasawneh, S. 2007. Self-efficacy and college students' perceptions and use of online learning systems. Computers in Human Behavior, 23, 175-191

Cascio M., Botta V., Anzaldi V. 2013. The role of self-efficacy and internal locus of control in online learning. Journal of e-Learning and Knowledge Society, v.9, n.3, 95-106

Cross,K.P. 1981. Adults as learners, San Francisco, Jossey-Bass

DeTure,M. 2004. Cognitive style and self-efficacy:Predicting student sucess in online distance education. The American Journal of Distance Education, 18(1), 21-38

Eachus,P. \& Cassidy, S. 2006. Development of the Web Users Self-Efficacy Scale (WUSE). Issues in Informing Science and Information Technology, 3, 199 - 209

Goulão, M ${ }^{\mathrm{a}}$ Fátima 2013. Virtual learning styles: does gender matter? Procedia Socail and Behavioral Sciences, 106, 3345 - 3354 


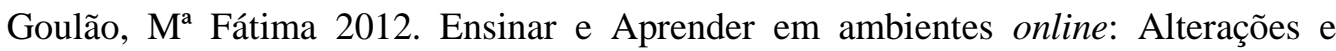
Continuidades na(s) prática(s) docente(s). In Moreira, J.A. \& Monteiro, A. (orgs). Ensinar e Aprender Online com Tecnologias Educativas (pp.15-30). Porto: Porto Editora


Gregory Papanikos \& Nicholas Pappas. Horizons in Education (pp.55 - 65). Atenas: ATINER

Knowles, M. Holton,E. \& Swanson, R. 2012. The adult learner. New York: Routledge Merriam,S. \& Brockett,R. 2007. The profession and practice of adult education. San Francisco: Jossey-Bass

Pintrich, P. R., Smith, D. A., Garcia, T., \& McKeachie, W. K. (1991). A manual for the use of the Motivated Strategies for Learning Questionnaire (MSLQ).University of Michigan.

Rogers,C.R. 1985.Tornar-se pessoa, Lisboa, Moraes Editores

Stone, D.1993. Overconfidence in Initial Self-Efficacy Judgments: Effects on Decision Processes and Performance. Organizational Behavior and Human Decision Processes, 59 (3), 452-474

Taipjutorus, W., Hansen, S., \& Brown, M. 2012. Investigating a Relationship between Learner Control and Self-efficacy in an Online Learning Environment. Journal of Open, Flexible, and Distance Learning, 16(1), 56 - 69

Zimmerman,B. 2000. Self-Efficacy: An Essential Motive to Learn. Contemporary Educational Psychology 25, 82-91

Appendix A. Self-efficacy Questions (adapted from MSLQ, Pintrinch et al, 1991)

\begin{tabular}{|c|c|}
\hline Sub-scale & Question Item \\
\hline Self-efficacy & $\begin{array}{l}\text { 1. I believe I will receive an excellent score on } \\
\text { seminar after learning about this topic in this } \\
\text { online learning context. } \\
\text { 2. I'm certain I can understand difficults } \\
\text { about Education and Literacy presented in this } \\
\text { online learning context. } \\
\text { 3. I'm confident I can understand basic concepts } \\
\text { about Education and Literacy presented in this } \\
\text { online learning context. } \\
\text { 4. I'm confident I can understand the most } \\
\text { complex material about the Education and } \\
\text { Literacy presented in this online learning } \\
\text { context. } \\
\text { 5. I'm confident I can do an excellent job in } \\
\text { meeting the goal for this task of learning about } \\
\text { Education and Literacy. } \\
\text { 6. I expect to do well learning about Education and } \\
\text { Literacy with this online learning context. } \\
\text { 7. I'm certain I can master the material on } \\
\text { Education and Literacy presented in this online } \\
\text { learning context. } \\
\text { 8. Considering the difficulty of the material of } \\
\text { Education and Literacy, the learning context, } \\
\text { and my skills, I think I will do well. }\end{array}$ \\
\hline
\end{tabular}

